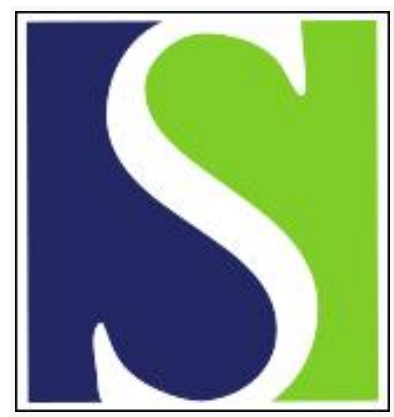

Scand J Work Environ Health 2014;40(2):203-209

https://doi.org/10.5271/sjweh.3386

Published online: 25 Sep 2013, Issue date: 01 Mar 2014

A prospective cohort study investigating an exposure-response relationship among vibration-exposed male workers with numbness of the hands

by Edlund M, Burström L, Gerhardsson L, Lundström R, Nilsson T, Sandén $H$, Hagberg $M$

This study on hand-arm-vibration (HAV) exposed workers spanned 16 years; exposure dose was assessed for each individual; and the study may contribute to knowledge about an exposure-response relationship between neurological symptoms and HAV exposure. Furthermore, to our knowledge, there are no other studies reporting incidence of numbness in hands among HAV-exposed workers or how it affects work performance.

Affiliation: Department of Occupational and Environmental Medicine, Sahlgrenska Academy, University of Gothenburg, Medicinaregatan 16, Po 414, SE-405 30 Gothenburg, Sweden. maria.edlund@amm.gu.se

Key terms: carpal tunnel syndrome; exposure; exposure-response relationship; hand-arm vibration; HAV; numbness; numbness of the hands; prospective cohort; prospective cohort study; sensorineural symptom; survival analysis; vibration; work performance

This article in PubMed: www.ncbi.nlm.nih.gov/pubmed/24067946

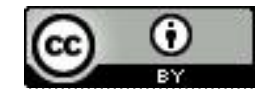




\title{
A prospective cohort study investigating an exposure-response relationship among vibration-exposed male workers with numbness of the hands
}

\author{
by Maria Edlund, MD, ${ }^{1}$ Lage Burström, PhD, ${ }^{2}$ Lars Gerhardsson, MD, ${ }^{1}$ Ronnie Lundström, PhD, ${ }^{2}$ \\ Tohr Nilsson, MD, ${ }^{2}$ Helena Sandén, MD, ${ }^{1}$ Mats Hagberg MD ${ }^{1}$
}

\begin{abstract}
Edlund M, Burström L, Gerhardsson L, Lundström R, Nilsson T, Sandén H, Hagberg M. A prospective cohort study investigating an exposure-response relationship among vibration-exposed male workers with numbness of the hands. Scand J Work Environ Health. 2014;40(2):203-209. doi:10.5271/sjweh.3386
\end{abstract}

Objective The aim of this study was to investigate the exposure-response relationship of hand-arm vibration (HAV) exposure to neurological symptoms (numbness) of the hand in a cohort of vibration-exposed workers.

Methods The baseline cohort comprised 241 office and manual workers with and without exposure to HAV. Numbness (the symptom or event) in the hand was assessed for all subjects at baseline and follow-ups after 5, 10, and 16 years. The workers were stratified into quartiles with no exposure in the first quartile and increasing intensity of exposure in quartiles 2-4 (groups 1-3). Data analysis was performed using survival analysis (time-to-event). Information on cumulative exposure and years of exposure to event was collected via questionnaires. Measurements were performed in accordance with the International Organization for Standardization (ISO) 5349-1.

Results The hazard ratio (HR) of risk of event (numbness) differed statistically significantly between the nonexposed group (group 0) and the two higher exposure groups (groups 2 and 3). There was also a significant ratio difference between the lowest exposure group (group 1) and the two higher groups. The ratio for group 1 was 1.77 [95\% confidence interval $(95 \%$ CI) $0.96-3.26$ ] compared with 3.78 (95\% CI 2.15-6.62) and 5.31 (95\% CI 3.06-9.20) for groups 2 and 3, respectively.

Conclusion The results suggest a dose-response relationship between vibration exposure and numbness of the hands. This underlines the importance of keeping vibration levels low to prevent neurological injury to the hands.

Key terms carpal tunnel syndrome; hand-arm vibration; HAV; sensorineural symptom; survival analysis; work performance.

Hand-arm vibration syndrome (HAVS), caused by handarm vibration (HAV), comprises both vascular and sensorineural symptoms with occurrence and progress seemingly independent of each other (1). Cases of HAVS have been reported mainly in countries with colder climates but also in tropical regions (2). The most evident sensorineural symptoms are tingling and numbness of the hand, and it has been tentatively suggested that the earliest symptoms are more likely to be neurological, preceding vascular symptoms (3).

Evidence for an exposure-response relationship for HAV exposure and neurological (sensorineural) symptoms is not very strong $(3,4)$. There are few longitudinal studies investigating this relationship and most of the reported studies have been cross-sectional (5-7). Establishing an exposure-response relationship would increase knowledge on vibration exposure and may help to avoid or minimize adverse health effects from HAV and quantify the risk for a certain exposure level.

The aim of this study was therefore to investigate the exposure-response relationship of HAV exposure to neurological symptoms (numbness) of the hand in a cohort of vibration-exposed workers. The majority of those with HAVS are considered to suffer from neurological symptoms, and the main interest in this study is for the neurological component of HAVS as the vascular disorder has been more extensively investigated $(3,8)$.

1 Department of Occupational and Environmental Medicine, University of Gothenburg, Gothenburg, Sweden.

2 Department of Public Health and Clinical Medicine, Occupational Medicine, Umeå University, Sweden.

Correspondence to: Maria Edlund, Department of Occupational and Environmental Medicine, Sahlgrenska Academy, University of Gothenburg, Medicinaregatan 16, Po 414, SE-405 30 Gothenburg, Sweden. [E-mail: maria.edlund@amm.gu.se] 


\section{Methods}

\section{Cohort}

The cohort consisted of male manual and office workers at an engineering plant in Sweden (9). Staggered start dates were used for the recruitment constituting the baseline: $1^{\text {st }}$ recruitment $=1$ January $1987,2^{\text {nd }}=31$ January 1992. Of a total of 500 office workers, 61 were randomly invited from the employee roster to participate in the study. Those accepting participation, along with all employed 112 manual workers, comprised the cohort of 151 subjects in 1987. In 1992 additional subjects were invited to participate, resulting in 241 subjects in total, of whom 60 were unexposed and 181 exposed (table 1). Occupations among the manual workers included mainly welders, tool grinders, turners and steel platers. Occupations among office workers included salespeople, managers, engineers, secretaries, and financial clerks. Exclusion criteria were age $\geq 55$ years (1987) and use of drugs with the potential to affect the nerve system and result in neurological symptoms.

Follow-ups were performed in 1992 (for those recruited in 1987) and 1997, 2002, and 2008. The cohort consisted of 241 subjects in 1992, and there were 220, 195 , and 197 subjects, respectively, at the follow-ups in 1997, 2002, and 2008.

Table 1 presents the study population for the different years of recruitment and follow-ups, including the number of exposed and unexposed subjects, subjects lost to follow-up, and returning subjects (10).

\section{Data collection on symptoms and exposure}

Symptoms. An experienced physician performed a standardized medical examination and interview focusing on neuromuscular symptoms and signs of the hand and upper extremity in $1987(\mathrm{~N}=151), 1992(\mathrm{~N}=241)$, 1997 and 2008. In 2002, there was no medical examination and data was collected via a questionnaire. During each follow-up, a questionnaire on symptoms of the hands was used. Numbness was defined as loss of sensation in the hands and/or fingers and was considered present if the subject answered positively to the screening question on suffering from numbness in the hand or fingers. The question on numbness was linked to a question on debut year. In this way it was possible to reach subjects who had missed out on a follow-up and then returned to the study. Where reported debut year differed on the various follow-up occasions, we selected the earliest year or the year that was reported most frequently as the year of debut. Subjects were also asked to report current or previous diagnosis of carpal tunnel syndrome (CTS), hand or arm trauma, and whether they considered the reported numbness
Table 1. Study population at baseline a and follow-up, 1987-2008.

\begin{tabular}{lrrrrr}
\hline Year & $1987^{\text {a }}$ & $1992^{\text {a }}$ & 1997 & 2002 & 2008 \\
\hline Total (N) & 151 & 241 & 220 & 195 & 197 \\
Exposed & 112 & 181 & 165 & 141 & 146 \\
Unexposed & 39 & 60 & 55 & 54 & 51 \\
Lost to follow-up (N) & & & & & \\
Exposed & & & 5 & 40 & 35 \\
Unexposed $_{\text {Returners }}{ }^{b}$ (N) & & & & 6 & 9 \\
Exposed $_{\text {Unexposed }}$ & & & & 8 & 26 \\
\hline
\end{tabular}

${ }^{a}$ Recruitment to the study was staggered (in 1987 and 1992) with 151 subjects recruited in 1987 and additional 90 subjects in 1992, resulting in $\mathrm{N}=241$ in 1992.

b Subjects who were included in 1987 and/or 1992, were lost to followup (1997 or 2002) but returned in 2002 or 2008. They are included in total subjects (and exposed or unexposed).

to affect their work performance. As previously mentioned, different expressions may be used to indicate sensorineural symptoms. However, for reasons of simplicity, and in order to secure a better response rate, only numbness was used in the study.

Exposure. The total exposure for each subject was assessed by collecting information via an interview, a questionnaire, and measurements. The workers were asked to write down the debut year of exposure, or age at first exposure, and how many minutes per day they had used vibrating tools, what sort of tools they had used, and what kind of work they had performed at the time. Leisure-time exposure was included (11).

Measurements were performed during representative working cycles. Time of registration varied between 2-45 minutes due to the length of the working cycle. The daily exposure was assessed by observations lasting 45-180 minutes in total and covering different tasks and parts of a working day. The observer noted the type and status of the tool (active or passive) and which hand was used. About 15 workers, believed to be representative of their group, were observed in each follow-up year. The surveyed workers mainly used grinders, hammers, and die grinders, and the mean vibration intensity $\left(\mathrm{m} / \mathrm{s}^{2}\right)$ was 5.5 [standard deviation (SD) 1.9], 10 (SD 2.9), and 1.5 (SD 0.3 ) respectively (12).

HAV exposure was reported in both time (minutes and hours) and acceleration level $\left(\mathrm{m} / \mathrm{s}^{2}\right)$, in accordance with International Organization for Standardization (ISO) guidelines (13). The cumulative HAV exposure dose (unit $\mathrm{h} \times \mathrm{m} / \mathrm{s}^{2}$ ) was defined as the product of hours (h) of exposure and the hand-arm acceleration value $\left(\mathrm{m} / \mathrm{s}^{2}\right)$. The cumulative dose until the onset, or event, of numbness was then divided by exposure years until the event to create an exposure measure for use when categorizing the different exposure groups for application in the survival analysis. This calculated exposure 
measure will represent an average intensity before symptom onset. For example, a worker using a handheld tool with a vibration exposure level of $2.5 \mathrm{~m} / \mathrm{s}^{2}$ [the EU action level (9) for a working day of 8 hours, the $\mathrm{A}(8)$ value] for 8 hours (a working day) and for 220 days (approximately corresponding to 1 working year) and continuing to do so for $5,10,15$, and 20 years will end up with exposure doses of $22000 \mathrm{~h} \times \mathrm{m} / \mathrm{s}^{2}$ (5 years), $44000 \mathrm{~h} \times \mathrm{m} / \mathrm{s}^{2}$ (10 years), $66000 \mathrm{~h} \times \mathrm{m} / \mathrm{s}^{2}$ (15 years), and $88000 \mathrm{~h} \times \mathrm{m} / \mathrm{s}^{2}$ (20 years). These cumulative doses can then be divided by exposure years until the event to produce an average intensity measure.

\section{Statistical analysis}

Hazard ratios (HR) were computed by Cox regression with adjustment for age (14). Time to the event was calculated from 18 years of age to the year or age of the event (symptom onset). We used the age of 18 because that was the average age of work start (mean 18.4; median 18.0; standard deviation (SD) 3.8). (The method of survival analysis is not exclusively used for the event of death, despite the terminology; the application is for different events such as development of symptoms or remission of tumors). The cumulative survival probability for each exposure group was illustrated in a survival curve (figure 1).

A one-way ANOVA with multiple comparisons (Tukey) was performed to detect any statistically significant differences in 1992 between groups with respect to age and alcohol consumption.

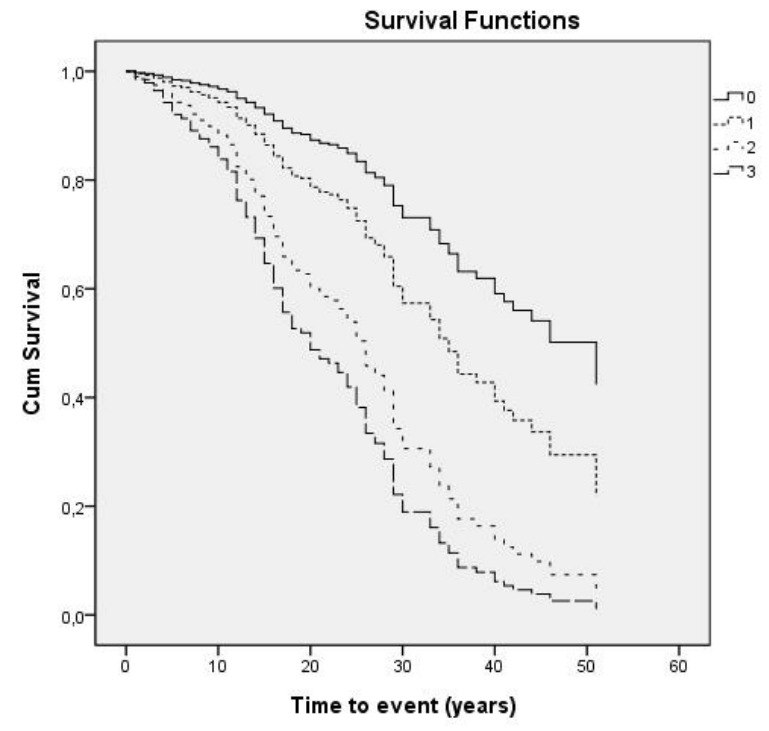

Figure 1. Survival functions with cumulative survival probability (cum survival) for groups with no or different exposure to hand-arm vibrations (HAV). The graph illustrates time to event of numbness. ( $0=$ unexposed; 1=low exposure; 2=medium exposure; $3=$ high exposure).
All statistical analyses were performed using PASW Statistics 18.0 (SPSS Inc, Chicago, IL, USA).

\section{Ethical approval}

Informed consent was obtained from each participant. The Regional Ethical Committee in the municipality of Umea approved the study, which was performed in accordance with the ethical standards laid down in the 1964 Declaration of Helsinki.

\section{Results}

Among exposed workers, the cumulative exposure dose until the event ranged from 825-107 $602 \mathrm{~h} \times \mathrm{m} / \mathrm{s}^{2}$ (mean 29 060, SD 25 170), and the number of exposure years to the event ranged from 3-56 (mean 30, SD 12). When stratifying the workers into quartiles based on the cumulative exposure dose per exposure years to the event (years at risk), the results were: (i) $1^{\text {st }}$ quartile: $\mathrm{N}=60$ unexposed subjects, incidence of numbness in the hand $=10.3$ cases of numbness per 1000 person-years at risk; (ii) $2^{\text {nd }}$ quartile: $\mathrm{N}=60,49-715 \mathrm{~h} \times \mathrm{m} / \mathrm{s}^{2}, 14.8$ per 1000; (iii) $3^{\text {rd }}$ quartile: $\mathrm{N}=60,716-1962 \mathrm{~h} \times \mathrm{m} / \mathrm{s}^{2}, 29.8$ per 1000; and (iv) $4^{\text {th }}$ quartile: $\mathrm{N}=59,1963-4576 \mathrm{~h} \times \mathrm{m} /$ $\mathrm{s}^{2}, 37.7$ per 1000 .

Two subjects were missing from the exposed group. There were 65 exposed and 19 unexposed subjects reporting debut of numbness before 1987 or between any of the follow-up years. The exposure dose until the event was then adjusted to the year of the event by using the exposure dose recorded at the next scheduled follow-up, multiplied by the quota of years to the event and years to the recorded exposure dose. However, there was no significant difference between these adjusted and non-adjusted values.

Descriptive characteristics of the study sample are presented in table 2 . The average age was slightly higher among the unexposed subjects compared with all exposed subjects and each subgroup. The difference for age between group 2 and the unexposed (group 0) was statistically significant $(\mathrm{P}=0.002)$. The groups (groups $0,1,2$, and 3) did not differ much regarding weight, height and body mass index (BMI). The use of alcohol and tobacco was somewhat higher among the exposed subjects, especially alcohol in subgroup 2 and tobacco in subgroup 3; however, the differences were not statistically significant. There was one subject with rheumatic disease and one subject with diabetes among both exposed and unexposed subjects. There was one subject with thyroid disease among the unexposed subjects.

During the study, there were emerging new cases of disease with a possibility for symptoms of numbness 
Table 2. Descriptive data on subjects in $1992(\mathrm{~N}=241)$. [BMI=body mass index]

\begin{tabular}{|c|c|c|c|c|c|c|c|c|c|c|}
\hline \multirow[t]{3}{*}{ Variable } & \multicolumn{8}{|c|}{$\begin{array}{l}\text { Exposed subjects } \\
\quad(\mathrm{N}=181)\end{array}$} & \multirow{2}{*}{\multicolumn{2}{|c|}{$\begin{array}{c}\text { Unexposed subjects } \\
(\mathrm{N}=60)\end{array}$}} \\
\hline & \multicolumn{2}{|c|}{ Total } & \multicolumn{2}{|c|}{ Group 1} & \multicolumn{2}{|c|}{ Group 2} & \multicolumn{2}{|c|}{ Group 3} & & \\
\hline & $\mathrm{N}$ & Mean & $\mathrm{N}$ & Mean & $\mathrm{N}$ & Mean & $\mathrm{N}$ & Mean & $\mathrm{N}$ & Mean \\
\hline Age (years) & & 39 & & 41 & & $37^{a}$ & & 39 & & $44^{a}$ \\
\hline Weight (kg) & & 79 & & 78 & & 78 & & 79 & & 80 \\
\hline Height (cm) & & 179 & & 180 & & 178 & & 178 & & 180 \\
\hline $\mathrm{BMI}$ & & 25 & & 24 & & 25 & & 25 & & 25 \\
\hline Alcohol 40\% ${ }^{\mathrm{b}}$ (cl/week) & & 24 & & 17 & & 37 & & 19 & & 17 \\
\hline Cigarette smokers & 58 & & 17 & & 19 & & 24 & & 17 & \\
\hline Rheumatic disease & 1 & & & & & & & & 1 & \\
\hline Thyroid disease & 0 & & & & & & & & 1 & \\
\hline Diabetes & 1 & & & & & & & & 1 & \\
\hline
\end{tabular}

a Multiple comparisons between groups with respect to age and alcohol use resulted in statistically significant difference for age between group 2 and group 0 (P-value 0.002).

b Calculated from total consumption of wine, beer, and spirits (alcohol 40\%). ("Strong beer" $1 \mathrm{cl}$ or spirits $0.13 \mathrm{cl}$; wine $1 \mathrm{cl}$ or spirits $0.3 \mathrm{cl}$ ).

other than from HAV. At the end of the study (2008), among the unexposed (group 0) there was one new case each of diabetes, thyroid disease, stroke, polyneuropathy, and an unspecified severe neurological disease. In the lowest exposure group (group 1), there was one case each of diabetes, alcoholic abuse, polyneuropathy, and an unspecified severe neurological disease. In the medium exposure group (group 2), there were two cases of thyroid disease and one case of diabetes. In the highest exposure group (group 3), there were two cases of stroke, two cases of diabetes, and one case of thyroid disease.

The risk of sensorineural symptoms (numbness) differed between the groups (tables 3 and 4). The difference was statistically significant between the unexposed group and the two higher exposure groups, and also between the lowest exposure group and the two higher groups. However, the difference was not statistically significant between the unexposed and the lowest exposure group or between the two higher exposure groups.

A comparison of unexposed and exposed workers with diagnosed CTS (from assessment by physician/health facility other than those in this study) and hand/arm trauma and reporting symptoms of numbness (between 1992-2008), showed a higher prevalence among exposed workers, especially for numbness affecting work performance (table 5).

Figure 1 presents survival curves of the different exposure groups based on cumulative dose to the event divided by exposure years to the event. It shows cumulative survival probability and time until the event of numbness. The outcome is unknown for those subjects who were lost to follow-up (censored). Not all subjects presented with the outcome before the end of the study. The median survival time for the unexposed subjects was 51 years (no SD or $95 \%$ CI given). For the exposed groups (ie, groups 1, 2, and 3), the median survival time was 33.0 (SD 3.07, 95\% CI 27.1-39.0), 25.0 (SD 3.74, 95\% CI 17.7-32.3), and 18.0 years (SD 2.56, 95\% CI 13.0-23.0), respectively.

\section{Discussion}

This longitudinal cohort study on HAV-exposed workers spanned prospectively 16 years (from 1992) and the exposure dose during this time was assessed for each individual. The long follow-up and careful exposure assessment give strength to the research. The study may be considered an important contribution to knowledge about an exposure-response relationship between neurological symptoms and HAV exposure. The study includes several different workers with different work tasks using a variety of tools, which may further strengthen the external validity.

In this study we compared different exposure groups (stratified into quartiles) to determine whether the amount of exposure contributes to developing symptoms. The outcome of time to symptom (numbness) onset differed between non-exposed subjects in the first quartile and the other three exposure groups with a stronger, statistically significant, association for the higher exposure groups compared with unexposed subjects.

The incidence of neurological symptoms of the hand among office workers with no vibration exposure reported in this study may seem fairly high. This may be explained by an increased awareness of symptoms due to participation in the study and their reported symptoms may also be milder. Even the incidence of neurological symptoms of the hand in vibration-exposed workers may be considered unacceptably high. The incidence of neurological symptoms was higher than that of vascular symptoms in the same cohort previously published (9). Numbness in the hand (fingers) has previously been reported to be a more common complaint than white fingers among HAV-exposed workers (15). The current reporting on numbness affecting work performance to a larger extent among exposed workers may be an indication that symptoms among exposed workers are more 
Table 3. Data on event of numbness for all groups. Subjects were divided into exposure groups based on cumulative dose to the event, divided by exposure years to the event $\left(\mathrm{h} \times \mathrm{m} / \mathrm{s}^{2}\right.$ per exposure years) $[95 \% \mathrm{Cl}=95 \%$ confidence interval].

\begin{tabular}{lcccccc}
\hline & $\mathrm{N}$ & Event & Censored & $\begin{array}{c}\mathrm{P}- \\
\text { value }\end{array}$ & Ratio & $95 \% \mathrm{Cl}$ \\
\cline { 2 - 7 } Group 0 a & 60 & 22 & 38 & & 1 & \\
Group 1 & 60 & 22 & 38 & 0.065 & 1.77 & $0.964-3.26$ \\
Group 2 & 60 & 36 & 24 & 0.000 & 3.78 & $2.15-6.62$ \\
Group 3 & 59 & 40 & 19 & 0.000 & 5.31 & $3.06-9.20$ \\
\hline a Unexposed & & & & & &
\end{tabular}

Table 4. Data on event of numbness for groups 1, 2, and 3 . Exposure groups based on cumulative dose to the event divided by exposure years to the event ( $\mathrm{h} \times \mathrm{m} / \mathrm{s}^{2}$ per exposure years). [ $95 \% \mathrm{Cl}=95 \%$ confidence interval]

\begin{tabular}{lrrr}
\hline & P-value & Ratio & $95 \% \mathrm{Cl}$ \\
\cline { 2 - 4 } Group 1 & & 1 & \\
Group 2 & 0.009 & 2.05 & $1.20-3.52$ \\
Group 3 & 0.000 & 2.91 & $1.73-4.92$ \\
\hline
\end{tabular}

Table 5. Number of subjects reporting diagnosed a carpal tunnel syndrome (CTS), hand/arm trauma and/or numbness affecting work performance among all 120 subjects who reported symptoms of numbness between 1992 and 2008.

\begin{tabular}{lccc}
\hline Variable & CTS & $\begin{array}{c}\text { Hand/arm } \\
\text { trauma }\end{array}$ & $\begin{array}{c}\text { Numbness affecting } \\
\text { work performance }\end{array}$ \\
\hline Unexposed workers & 0 & 1 & 3 \\
Exposed workers & 7 & 4 & 30
\end{tabular}

a Diagnosed from assessment by physician/health facility other than those in present study.

severe and/or that the work requires more demanding manual tasks in general. Other explanations such as additional effects from psychological mechanisms may also be plausible (16). It is further possible that workers with high exposure are more aware of signals and symptoms from their hands because they know that vibrations are potentially harmful. An effect of aging may also be a probable explanation for all participants.

To our knowledge there are no other studies reporting incidence of numbness in the hands, and this complicates a comparison to other studies. There are some studies reporting on incidence of CTS (17-19). However, comparisons to these incidences may be difficult to interpret. Atroshi et al (17) report incidence of CTS in a Swedish general population. Presenting their data as US-standardized annual incidence among men, they report an incidence of 125 per 100000 persons. In a Dutch general population, the incidence rate for CTS was 2.3 cases per 1000 person-years (18).

The present findings, which suggest that a doseresponse relationship exists, match the results of similar previous longitudinal studies showing evidence for a dose-response relationship between HAV exposure and neurological (sensorineural) impairment of the hand (4, 20,21). However, this relationship has been unclear and has not yet been fully established (3). Bovenzi requests prospective cohort studies to establish this relationship. (3). We believe that the present study may be an important contribution to our knowledge in this area. A healthy worker effect among the two groups of higher exposed workers may be a cautious explanation as to why the difference between these groups is not statistically significant.

HAV-exposed workers often experience tingling and numbness in their fingers (22). These symptoms can be intermittent or have a short duration if caused by the vibrations per se. However, the associated question on the debut year of symptoms may give stronger credibility to our findings. The concept of numbness in the hand can be defined as an absence or loss of tactile sensation and may be associated with other symptoms like prickling or burning sensations, even though this may not be the only relevant definition. Patients can easily interpret symptoms differently or may have another definition for the symptom, which may confuse the picture of how common the HAVS is (23).

The exposure may not be entirely limited to vibration but may also include ergonomic factors like power grip and repetitive hand-wrist movements (3).

\section{Limitations}

Some of the subjects in the present study were lost to follow-up (table 1), also there was a long time between follow-ups, when subjects were asked about their symptoms of numbness, which may have resulted in recall bias. On the other hand, we had several follow-ups in order to reach those subjects lost at one follow-up. This gave subjects several opportunities to recall debut of symptoms. The subjects who were lost to follow-up(s) as well as the returners were analyzed for age and exposure; however, they did not differ from those who were not lost to follow-up(s) (10).

During the study period, there were emerging new cases of disease with the potential to cause numbness. The number of cases was between three and five new cases in each group and thus did not vary much. In order to keep as many workers as possible in the study and to avoid decreased power in the analyses these cases were not excluded.

The symptom of numbness in the hand is associated with both HAVS and CTS, and is therefore useful as an outcome (response) measure for neurological impairment as it shows the relationship between dose of exposure and response. The neurological symptoms of HAVS and CTS are very alike and often impossible 
to tell apart (4). Though it may be somewhat unspecific, it is important to investigate the impact of HAV on neurological symptoms as it appears that sensorineural symptoms or injuries are more resistant to improvement than are vascular disorders after cessation of exposure to $\operatorname{HAV}(24,25)$.

\section{Concluding remarks}

The results show statistically significant differences in ratio between unexposed individuals and individuals with higher exposure as well as between the lower exposure group and the higher exposure groups, suggesting that a dose-response relationship exists between vibration exposure and numbness of the hands. This underlines the importance of keeping vibration levels low to prevent neurological injuries to the hands.

\section{Acknowledgment}

The Swedish Council for Working Life and Social Research supported this research. The authors declare no competing interests.

\section{References}

1. Pelmear PL: The clinical assessment of hand-arm vibration syndrome. Occup Med-Oxford. 2003;53(5):337-41. http:// dx.doi.org/10.1093/occmed/kqg007

2. Su TA, Hoe VC, Masilamani R, Awang Mahmud AB: Handarm vibration syndrome among a group of construction workers in Malaysia. Occup Environ Med. 2011; 68(1):58-63. http://dx.doi.org/10.1136/oem.2009.052373.

3. Bovenzi M: Exposure-response relationship in the hand-arm vibration syndrome: an overview of current epidemiology research. Int Arch Occup Environ Health. 1998; 71(8):509-19. http://dx.doi.org/10.1007/s004200050316.

4. Sauni R, Paakkonen R, Virtema P, Toppila E, Uitti J: Doseresponse relationship between exposure to hand-arm vibration and health effects among metalworkers. Ann Occup Hyg. 2009;53(1):55-62. http://dx.doi.org/10.1093/annhyg/men075.

5. Heaver C, Goonetilleke KS, Ferguson H, Shiralkar S: Handarm vibration syndrome: a common occupational hazard in industrialized countries. J Hand Surg Eur Vol. 2011;36(5):354 63. http://dx.doi.org/10.1177/1753193410396636.

6. Lundstrom R, Nilsson T, Burstrom L, Hagberg M: Exposure-response relationship between hand-arm vibration and vibrotactile perception sensitivity. Am J Ind Med. 1999;35(5):456-64. http://dx.doi.org/10.1002/(SICI)10970274(199905)35:5<456::AID-AJIM2>3.0.CO;2-\#.

7. Barregard L, Ehrenstrom L, Marcus K: Hand-arm vibration syndrome in Swedish car mechanics. Occup Environ Med. 2003;60(4):287-94. http://dx.doi.org/10.1136/oem.60.4.287.

8. Burke FD, Lawson IJ, McGeoch KL, Miles JN, Proud G: Carpal tunnel syndrome in association with hand-arm vibration syndrome: a review of claimants seeking compensation in the Mining Industry. J Hand Surg Br. 2005;30(2):199-203. http:// dx.doi.org/10.1016/j.jhsb.2004.11.007.

9. Hagberg M, Burstrom L, Lundstrom R, Nilsson T. Incidence of Raynaud's phenomenon in relation to hand-arm vibration exposure among male workers at an engineering plant a cohort study. J Occup Med Toxicol. 2008;3:13. http://dx.doi. org/10.1186/1745-6673-3-13.

10. Sanden H, Jonsson A, Wallin BG, Burstrom L, Lundstrom $\mathrm{R}$, Nilsson $\mathrm{T}$, et al.: Nerve conduction in relation to vibration exposure - a non-positive cohort study. J Occup Med Toxicol. 2010;5:21. http://dx.doi.org/10.1186/1745-6673-5-21.

11. Burstrom L, Lundstrom R, Hagberg M, Nilsson T: Comparison of different measures for hand-arm vibration exposure. Safety Sci. 1998;28(1):3-14. http://dx.doi.org/10.1016/S09257535(97)00059-3.

12. Nilsson T, Burstrom L, Hagberg M: Risk assessment of vibration exposure and white fingers among platers. Int Arch Occup Environ Health. 1989;61:473-81. http://dx.doi. org/10.1007/BF00386482.

13. International Organization for Standardization. ISO 53491: Mechanical vibration - Measurement and evaluation of human exposure to hand-transmitted vibration - Part 1: Genereral guidelines. Geneva: International Organisation for Standardisation; 2001.

14. Eric Vittinghoff DVG, Stephen C. Shiboski, Charles E. McCulloch. Regression Methods in Biostatistics. Linear, Logistic, Survival, and Repeated Measures Models. K. Dietz MG, K. Krickeberg, J. Samet, A. Tsiatis, editor: Springer; 2010.

15. Palmer K, Crane G, Inskip H. Symptoms of hand-arm vibration syndrome in gas distribution operatives. Occup Environ Med. 1998;55(10):716-21. http://dx.doi.org/10.1136/ oem.55.10.716.

16. Edlund M, Gerhardsson L, Hagberg M. Physical capacity and psychological mood in association with self-reported work ability in vibration-exposed patients with hand symptoms. J Occup Med Toxicol. 2012;7(1):22. http://dx.doi. org/10.1186/1745-6673-7-22.

17. Atroshi I, Englund M, Turkiewicz A, Tagil M, Petersson IF. Incidence of physician-diagnosed carpal tunnel syndrome in the general population. Arch Intern Med. 2011; 171(10):943-4. http://dx.doi.org/10.1001/archinternmed.2011.203.

18. Dieleman JP, Kerklaan J, Huygen FJ, Bouma PA, Sturkenboom MC. Incidence rates and treatment of neuropathic pain conditions in the general population. Pain. 2008;137(3):681-8. http://dx.doi.org/10.1016/j.pain.2008.03.002.

19. Wolf JM, Mountcastle S, Owens BD. Incidence of carpal tunnel syndrome in the US military population. Hand (N Y). 2009;4(3):289-93. http://dx.doi.org/10.1007/s11552-0099166-y.

20. Jang JY, Kim S, Park SK, Roh J, Lee TY, Youn JT. Quantitative 
exposure assessment for shipyard workers exposed to hand-transmitted vibration from a variety of vibration tools. AIHA J (Fairfax, Va). 2002;63(3):305-10. http://dx.doi org/10.1080/15428110208984718.

21. Bovenzi M, Ronchese F, Mauro M. A longitudinal study of peripheral sensory function in vibration-exposed workers. Int Arch Occup Environ Health. 2011; 84(3):325-34. http:// dx.doi.org/10.1007/s00420-010-0549-8.

22. Friden J. Vibration damage to the hand: clinical presentation, prognosis and length and severity of vibration required. J Hand Surg Br. 2001;26(5):471-4. http://dx.doi.org/10.1054/ jhsb.2001.0633.

23. Griffin MJ. Measurement, evaluation, and assessment of peripheral neurological disorders caused by hand-transmitted vibration measurement, evaluation, and assessment of peripheral neurological disorders caused by hand-transmitted vibration. Int Arch Occ Env Hea. 2008;81(5):559-73. http:// dx.doi.org/10.1007/s00420-007-0253-5.

24. Futatsuka M, Ueno T, Sakurai T. Cohort study of vibrationinduced white finger among Japanese forest workers over 30 years. Int Arch Occup Environ Health. 1989; 61(8):503-6. http://dx.doi.org/10.1007/BF00683119.

25. Koskimies K, Pyykko I, Starck J, Inaba R. Vibration syndrome among Finnish forest workers between 1972 and 1990. Int Arch Occup Environ Health. 1992; 64(4):251-6. http://dx.doi. org/10.1007/BF00378282.

Received for publication: 15 April 2013 